\title{
ANALISIS KEKERINGAN HIDROLOGI BERDASARKAN METODE MOISTURE ADEQUACY INDEX (MAI) DI DAERAH ALIRAN SUNGAI TEMON KABUPATEN WONOGIRI
}

\author{
Esthi Rahmawati RW'1), Rintis Hadiani2), Solichin'3) \\ 1) Mahasiswa Jurusan Teknik Sipil Universitas Sebelas Maret Surakarta \\ 2),3)Akademisi Program Studi Teknik Sipil Universitas Sebelas Maret Surakarta \\ Jl. Ir. Sutami 36 A, Surakarta 57126 \\ Email : esthirahmaa@gmail.com
}

\begin{abstract}
Abstrak
Wonogiri merupakan salah satu Kabupaten di Provinsi Jawa Tengah yang memiliki curah hujan rendah sehingga wilayah ini berpotensi terjadi bencana kekeringan karena ketersediaan air terus menurun, salah satu daerah aliran sungai yang terdampak yaitu DAS Temon. Penelitian ini bertujuan untuk mengetahui indeks kekeringan hidrologi dan ketersediaan air. Salah satu cara untuk mengatasi dampak bencana kekeringan yaitu dengan memperhitungkan indeks kekeringan hidrologi dari Daerah Aliran Sungai (DAS) Temon. Indeks kekeringan hidrologi dihitung berdasarkan Metode Moisture Adequacy Index (MAI) yang merupakan perbandingan antara evapotranspirasi potensial dan aktual dengan klasifikasi menurut CAZRI (Central Arid Zone Research Institute), sedangkan perhitungan ketersediaan air menggunakan metode FJ Mock dengan output debit 15 harian. Dari hasil analisa perhitungan tersebut dibuat sebuah peta persebaran menggunakan Software ArcGIS selain itu dibuat grafik korelasi antara debit dan indeks. dari hasil analisis perhitungan indeks yang telah dilakukan nilai minimum indeks kekeringan yaitu 0,73 yang masuk dalam kriteria kering ringan sedangkan nilai maksimum indeks sebesar 0,97 dengan kriteria normal. Trend bencana kekeringan selanjutnya dapat diprediksi melalui grafik hubungan antara debit dan indeks dengan persamaan linier y $=$ 0,7118x - 0,5256 dimana y adalah debit dan $\mathrm{x}$ adalah indeks.
\end{abstract}

Kata kunci : Pemetaan kekeringan, FJ Mock, Moisture Adequacy Index (MAI)

\begin{abstract}
Abstrack
Wonogiri is one of the Regencies in Central Java Province that has low rainfall, so this area has higher potential to occur drought due to the decreasing of water availability, one of the affected river basin that is Temon Watershed. This study aims determine the index of bydrological drought and water availability. One way to find out the impact of drought disaster is make an analysis of hydrological drought index in Temon Watershed. The bydrological drought index is calculated based on the Moisture Adequacy Index (MAI), which is a comparison between potential and actual evapotranspiration with the classification of drought using CAZRI (Central Arid Zone Research Institute), while water availability calculated using FJ Mock with 15 days discharge output. From the result of the calculation analysis is made a dipersion map using ArcGIS Software besides created graph of correlation between the water availability and index. From result of calculation of index which have been done minimum value of dryness index that is 0,73 which enter in dry criteria lightness while maximum index value equal to 0,97 with normal condition. The trend of drought disaster can then be predicted by graph of the relationship between debit and index with linier equation $y=0,7118 x-0,5256$ where $y$ is the discharge and $x$ is the index.
\end{abstract}

Keywords : Drought Mapping, FJ Mock, Moisture Adequacy Index (MAI)

\section{PENDAHULUAN}


Kekeringan merupakan masalah menahun yang terjadi di Indonesia tetapi penanganan untuk pencegahan begitu lamban dikarenakan susahnya identifikasi lama dan waktu datangnya permasalahan ini. Salah satu kawasan yang yang teridentifikasi permasalahan kekeringan yang semakin meningkat dari tahun ke tahun yaitu Daerah Aliran Sungai Temon yang mana daerah ini merupakan daerah yang alirannya terhimpun masuk kedalam waduk Gajah Mungkur Wonogiri.

Kekeringan dapat diidentifikasi melalui pendekatan debit yang tersedia, interaksi iklim terkait dengan pola hujan atau debit yang pernah terjadi dikarenakan ada kecenderungan bahwa pola hujan atau debit akan dapat berulang dalam kurun waktu tertentu (Hadiani, 2009).

Kekeringan erat kaitannya dengan ketersediaan air dalam suatu wilayah, dalam penelitian ini analisis ketersediaan air menggunakan metode FJ.Mock dengan output debit 15 harian. Sedangkan untuk perhitungan indeks kekeringan menggunakan metode Moisture Adequacy Index (MAI) yang mengukur kelembaban berdasarkan kelembaban suatu wilayah, metode ini dianalisis berdasarkan perbandingan besar evapotranspirasi potensial dan aktual (A. A. L. N. Sarma, 1983). Dari hasil perhitungan tersebut maka akan dibuat grafik korelasi antara indeks dan debit serta peta persebaran kekeringan menggunakan Software ArcGIS.

Tujuan dari analisis dalam penilitian ini yaitu mengetahui indeks kekeringan hidrologi serta ketersediaan air dalam Daerah Aliran Sungai (DAS) Temon, mengetahui pemetaan persebaran kekeringan.

\section{LANDASAN TEORI}

\section{Dasar Teori}

\section{Uji Kelengkapan Data}

Data yang ideal adalah data yang disajikan secara lengkap, tetapi dalam pelaksanaannya sering dijumpai missing record atau incomplete record. Data hujan yang berasal dari stasiun pengamat hujan harian kadang tidak tersedia secara lengkap dikarenakan alat yang bekerja kurang baik, kelalaian petugas, data hilang, atau data tidak terbaca. Sehingga, data hujan yang hilang tersebut dapat diisi menggunakan bantuan data perkiraaan yang tersedia di 3 (tiga) pos stasiun terdekat di sekitar stasiun yang kehilangan data tersebut. Data yang hilang juga dapat dicari menggunakan metode Reciprocal Method. Perhitungan data hujan yang hilang menggunakan metode ini lebih baik karena memperhitungkan jarak antar stasiun. Cara perhitungannya dapat dilihat pada Persamaan [1].

$P_{x}=\frac{\sum_{i=1}^{n} \frac{P i}{L i^{2}}}{\sum_{i=1}^{n} \frac{1}{L i^{2}}}$

dengan :

Li $=$ Jarak antar stasiun.

\section{Uji Kepanggahan Data Hujan}

Uji kepanggahan data bertujuan untuk memastikan data yang nantinya akan diolah konsisten atau tidak, jika setelah diuji kepanggahannya ternyata tidak konsisten maka data tersebut tidak dapat digunakan sehingga perlu adanya penggantian atau pengisian data yang hilang. Uji kepanggahan data pada penelitian ini dilakukan dengan metode Kurva Masa Ganda (Double Mass Curve), merupakan metode yang digunakan dengan cara membandingkan hujan tahunan kumulatif di stasiun $y$ terhadap stasiun referensi $x$. Stasiun referensi bernilai rata-rata dari stasiun yang berada di dekatnya, kemudian selanjutnya nilai kumuatif tersebut digambarkan pada diagram koordinat kartesian untuk memeriksan perubahan kemiringan diagram yang terbentuk. Apabila kurva yang terbentuk patah maka pencatatan di stasiun y tidak konsisten maka perlu diadakan koreksi dengan cara mengalikan data setelah kurva berubah dengn perbandingan kemiringan setelah dan sebelum kurva patah. 


\section{Hujan Wilayah}

Metode yang digunakan dalam penelitian ini yaitu Metode Polygon Thiessen yang mana dalam metode ini memperhitungkan bobot masing-masing stasiun hujan yang mewakili luasan di sekitarnya. Pada suatu luasan di dalam DAS dianggap bahwa hujan adalah sama dengan yang terjadi pada stasiun yang terdekat, sehingga hujan yang tercatat pada stasiun tersebut mewakili hujan pada luasan tersebut. Hujan rerata DAS dapat dihitung menggunakan Persamaan [2] :

$P=\sum_{i=1}^{n} P_{i} W_{i}$

dengan :

$\mathrm{P} \quad=$ Hujan rata-rata DAS;

$\mathrm{P}_{i} \quad=$ Kedalaman hujan di stasiun $i$

$\mathrm{W}_{i} \quad$ = Bobot stasiun;

$\mathrm{A}_{i} \quad=$ Luas daerah yang diwakili stasiun $i$;

$\mathrm{A} \quad=$ Luas DAS;

$\mathrm{n} \quad=$ Jumlah stasiun hujan.

\section{Evapotransprasi}

Evapotranspirasi merupakan peristiwa kehilangan air total akibat penguapan dari muka tanah dan transpirasi tanaman (Kriteria Perencanaan Jaringan Irigasi KP - 01). Evapotranspirasi dihitung berdasarkan metode Thornthwaite - Matter dengan input data klimatologi berupa temperature rata-rata.

Perhitungan evapotranspirasi potensial dapat dihitung menggunakan Persamaan [3] - [5] :

PET $=$

$16,2\left[\frac{\left(10 T_{a}\right)}{I}\right]^{a}$

$I=\sum_{i=l}^{12}\left[\left(\frac{T m}{5}\right)\right]^{1,514}$

$a=0,492+0,0179 I-0,0000771 I^{2}+0,000000675 I^{3}$.

dengan :

$\operatorname{Tm}=$ suhu rata $-\operatorname{rata}\left({ }^{\circ} \mathrm{C}\right)$,

I $\quad=$ indeks panas

\section{Ketersediaan Air}

Perhitungan ketersediaan air dihitung menggunakan metode FJ Mock dengan komponen proses yang berupa data hujan,evapotranspirasi, keseimbangan air di permukaan tanah, serta tampungan air tanah (Mock, 1973).

Data dan asumsi yang diperlukan dalam perhitungan metode Mock yaitu sebagai berikut:

a. Data curah hujan $(\mathrm{P})$

b. Evapotranspirasi terbatas (Et), dapat dihitung menggunakan Persamaan [6] - [7].

$\mathrm{Et}=\mathrm{Ep}-\mathrm{E}$...

$\mathrm{E}=\operatorname{Ep} \times(\mathrm{m} / 20) \times(18-\mathrm{n})$

c. Faktor karakteristik hidrologi faktor bukaan lahan

d. Luas daerah tangkapan hujan

e. Kelembaban tanah (SMC), dapat dihitung menggunakan Persamaan [8] - [9].

$\mathrm{SMC}(\mathrm{n})=\mathrm{SMC}-\mathrm{SS}(\mathrm{n})$

$\mathrm{Ws}=$ As - IS

f. Kandungan air tanah

g. Keseimbangan air di permukaan tanah

h. Aliran dan penyimpanan air tanah, dapat dihitung menggunakan Persamaan [10] - [11].

$\mathrm{Vn}=\mathrm{kx} \mathrm{V}_{\mathrm{n}-1}+0,5(1+\mathrm{k}) \mathrm{I}$ 
$\mathrm{Vn}=\mathrm{v}_{\mathrm{n}}-\mathrm{v}_{\mathrm{n}-1}$

i. Aliran sungai

Interflow $\quad=$ infiltrasi - volume air tanah

Direct run off $=$ water surplus - infiltrasi

Base flow = aliran yang selalu ada sepanjang tahun

Run off $\quad$ interflow + direct run off + base flow

Dengan :

$\mathrm{E}=$ Beda antara evapotranspirasi potensial dengan evapotranspirasi terbatas $(\mathrm{mm})$;

Et $\quad=$ Evapotranspirasi terbatas $(\mathrm{mm})$;

Ep $\quad=$ Evapotranspirasi potensial $(\mathrm{mm})$;

$\mathrm{m} \quad=$ Singkapan lahan (Exposed surface);

$\mathrm{n} \quad=$ Jumlah hari hujan.

SMC $=$ Kelembaban tanah;

SMC (n) = Kelembaban tanah periode ke $\mathrm{n}$;

$\mathrm{SMC}(\mathrm{n}-1) \quad=$ Kelembaban tanah periode ke n-1;

SS $\quad=$ Soil Storage $(\mathrm{mm})$;

As $\quad=$ Air hujan yang mencapai permukaan tanah.

$\mathrm{V}_{\mathrm{n}} \quad=$ Volume air tanah periode ke $\mathrm{n}$;

$\mathrm{K}=\mathrm{qt} / \mathrm{qo}=$ faktor resesi aliran tanah;

qt $\quad=$ aliran air tanah pada waktu periode ke $\mathrm{t}$;

qo $\quad=$ aliran air tanah pada awal periode (periode ke 0 );

$\mathrm{v}_{\mathrm{n}-1} \quad=$ volume air tanah periode ke $(\mathrm{n}-1)$;

vn $\quad=$ perubahan volume aliran air tanah.

\section{Moisture Adequacy Index (MAI)}

Keseimbangan air menggambarkan tentang masuknya air dalam bentuk curah hujan dan hilangnya air dalam bentuk penguapan dan evapotranspirasi. Metode analisis kekeringan ini dapat dicari dengan menghitung perbandingan antara evapotranspirasi aktual dan evapotranspirasi potensial (M. Sambasiva Rao et.al, 2016).

Indeks kekeringan menggunakan metode Moisture Adequacy Index dapat dihitung menggunakan persamaan [12]

$M A I=\frac{A E}{P E}$

dengan :

MAI = Moisture Adequacy Index (MAI),

$\mathrm{AE} \quad=$ Actual Evapotrasnpiration,

$\mathrm{PE} \quad=$ Potensial Evapotranspiration.

\section{Kriteria Kering}

Tabel 1. Klasifikasi kekeringan berdasarkan indeks kekeringan.

\begin{tabular}{ll}
\hline $\mathbf{A E} / \mathbf{P E}$ & Intensitas Kekeringan \\
\hline$>1,00$ & Basah \\
\hline $0,90-1,00$ & Normal \\
\hline $0,79-0,89$ & Kekeringan ringan \\
\hline $0,50-0,78$ & Kekeringan sedang \\
\hline$<0,50$ & Kekeringan parah \\
\hline
\end{tabular}

\section{METODE PENELITIAN}


Penelitian ini dilaksanakan di Daerah Aliran Sungai (DAS) Temon yang terletak pada 7o 49' 48' - 70 52' 51,88' LS dan 110 49' 56,70" - 110 52' 38,5” BT Kabupaten Wonogiri,Provinsi Jawa Tengah. Data yang dibutuhkan dalam analisis perhitungan penelitian yaitu data curah hujan harian beserta koordinat stasiun hujan DAS Temon (Batuwarno, Baturetno, Ngancar) kurun waktu 15 Tahun (2003 - 2017), peta rupa bumi skala 1 : 25000, data klimatologi dengan rentang waktu 15 Tahun (2003 - 2017). tahapan penyelesaian studi yaitu pengumpulan data sekunder, pengisian data hilang menggunakan metode Reciprocal, pengujian kepanggahan data menggunakan kurva masa ganda, perhitungan evapotranspirasi menggunakan metode Thornthwaite untuk evapotranspirasi potensial dan pendekatan neraca air mock untuk evapotranspirasi aktual, perhitungan ketersediaan air menggunakan metode FJ Mock, perhitungan indeks kekeringan, pemetaan indeks kekeringan, pembuatan grafik korelasi antara debit dan indeks kekeringan.

\section{HASIL DAN PEMBAHASAN}

\section{Pengujian Konsistensi Data}

Berdasarkan hasil uji konsistensi data hujan menggunakan kurva massa ganda pada Daerah Aliran Sungai (DAS) Temon tidak ditemukan adanya data yang menyimpang sehingga data hujan dianggap konsisten dan dapat digunakan untuk perhitungan indeks kekeringan menggunakan metode Moisture Adequacy Indeks.

\section{Analisis Hujan Titik menjadi Hujan Wilayah}

Untuk menentukan hujan wilayah di Daerah Aliran Sungai (DAS) Temon menggunakanmetode Polygon Thiessen dengan tinjauan 3 stasiun hujan dan luasan DAS Temon sebesar 54,948 $\mathrm{km}^{2}$. Setelah dianalisa didapatkan koefisien thiessen dari masing-masing stasiun yaitu Pos Batuwarno (115a) dengan luas 17,794 maka koefisien thiessen sebesar 0,3238; Pos Baturetno (115) dengan luas 17,679 maka koefisien thiessen sebesar 0,3217; Pos Ngancar (115b) dengan luas 19,475 maka koefisien thiessen sebesar 0,354.

\section{Evapotranspirasi Potensial}

Evapotranspirasi dihitung menggunakan metode Tornthwaite Matter. Besar nilai evapotranspirasi potensial berada pada rentang nilai 19,2463 mm hingga 297,6175 mm.

\section{Perhitungan Ketersediaan Air}

Perhitungan ketersediaan air dihitung berdasarkan metode FJ Mock dengan input berupa data curah hujan dan parameter berupa faktor resensi aliran tanah (k), kapasitas kelembaban (SMC), koefisien infiltrasi (I), dan tampungan awal (IS).

\section{Evapotranspirasi Aktual}

Perhitungan evapotranspirasi aktual menggunakan pendekatan metode neraca air FJ. Mock, dengan parameter berupa banyaknya jumlah hari hujan (n) dan asumsi exposed surface (m). Besar nilai evapotranspirasi aktual berada pada rentang 15,2046 $\mathrm{mm}$ hingga 230,6536 $\mathrm{mm}$.

\section{Indeks Kekeringan}

Indeks kekeringan diperoleh berdasarkan analisis perhitungan menggunakan metode Moisture Adequacy Index merupakan perbandingan antara evapotranspirasi aktual dengan evapotranspirasi potensial. Indeks kekeringan berada pada rentang nilai 0,73 hingga 0,97 . 


\section{Klasifikasi Kekeringan}

Indeks kekeringan yang telah dihitung diklasifikasikan kekeringannya berdasarkan CAZRI (Central Arid Zone Research Institute) dalam Tabel 1. Pada penelitian ini klasifikasi kekeringan berada dalam kondisi normal hingga kekeringan sedang. Perhitungan pada tahun 2017 disajikan dalam Tabel 2.

Tabel 2. Hasil Perhitungan Tahun 2017

\begin{tabular}{llllll}
\hline 2017 & $\begin{array}{c}\text { Evapotranspirasi } \\
\text { Potensial (EP) }\end{array}$ & $\begin{array}{c}\text { Evapotranspirasi } \\
\text { Aktual (EA) }\end{array}$ & Debit (Q) & $\begin{array}{c}\text { Indeks } \\
\text { MAI }\end{array}$ & Kriteria \\
\hline JAN I & 141,5428 & 125,2654 & 0,0588 & 0,8850 & Kekeringan Ringan \\
\hline JAN II & 133,6280 & 122,2697 & 0,1497 & 0,9150 & Normal \\
\hline FEB I & 134,3652 & 123,6160 & 0,5120 & 0,9200 & Normal \\
\hline FEB II & 150,3714 & 127,0638 & 0,0736 & 0,8450 & Kekeringan Ringan \\
\hline MAR I & 151,1136 & 130,7132 & 0,0479 & 0,8650 & Kekeringan Ringan \\
\hline MAR II & 153,7159 & 130,6586 & 0,0337 & 0,8500 & Kekeringan Ringan \\
\hline APR I & 152,4168 & 121,1713 & 0,1258 & 0,7950 & Kekeringan Ringan \\
\hline APR II & 157,2641 & 130,5292 & 0,0271 & 0,8300 & Kekeringan Ringan \\
\hline MEI I & 144,6057 & 112,7925 & 0,0203 & 0,7800 & Kekeringan Sedang \\
\hline MEI II & 143,2542 & 109,5895 & 0,0143 & 0,7650 & Kekeringan Sedang \\
\hline JUN I & 153,9676 & 117,7852 & 0,0114 & 0,7650 & Kekeringan Sedang \\
\hline JUN II & 141,5068 & 108,9602 & 0,0086 & 0,7700 & Kekeringan Sedang \\
\hline JUL I & 124,4638 & 90,8586 & 0,0064 & 0,7300 & Kekeringan Sedang \\
\hline JUL II & 116,8146 & 89,3631 & 0,0045 & 0,7650 & Kekeringan Sedang \\
\hline AGS I & 135,0163 & 100,5871 & 0,0036 & 0,7450 & Kekeringan Sedang \\
\hline AGS II & 124,2947 & 90,7351 & 0,0025 & 0,7300 & Kekeringan Sedang \\
\hline SEP I & 146,4436 & 106,9039 & 0,0020 & 0,7300 & Kekeringan Sedang \\
\hline SEP II & 152,8233 & 120,7304 & 0,0015 & 0,7900 & Kekeringan Ringan \\
\hline OKT I & 140,9809 & 112,0798 & 0,0011 & 0,7950 & Kekeringan Ringan \\
\hline OKT II & 158,9231 & 122,3708 & 0,0008 & 0,7700 & Kekeringan Sedang \\
\hline NOV I & 180,9323 & 148,3645 & 0,0006 & 0,8200 & Kekeringan Ringan \\
\hline NOV II & 175,3237 & 162,1744 & 0,7880 & 0,9250 & Normal \\
\hline DES I & 154,9277 & 127,8154 & 0,0555 & 0,8250 & Kekeringan Ringan \\
\hline DES II & 147,6907 & 132,1832 & 0,1450 & 0,8950 & Normal \\
\hline & & & & & \\
\hline
\end{tabular}

\section{Grafik Korelasi Debit dan Indeks}

Grafik korelasi antara debit ketersediaan air dan indeks kekeringan dibuat bertujuan untuk mengetahui trend bencana kekeringan yang terjadi di Daerah Aliran Sungai (DAS) Temon. Grafik hubungan antara debit ketersediaan air dan indeks kekeringan Gambar 1. 


\section{GRAFIK HUBUNGAN ANTARA DEBIT DAN INDEKS KEKERINGAN}

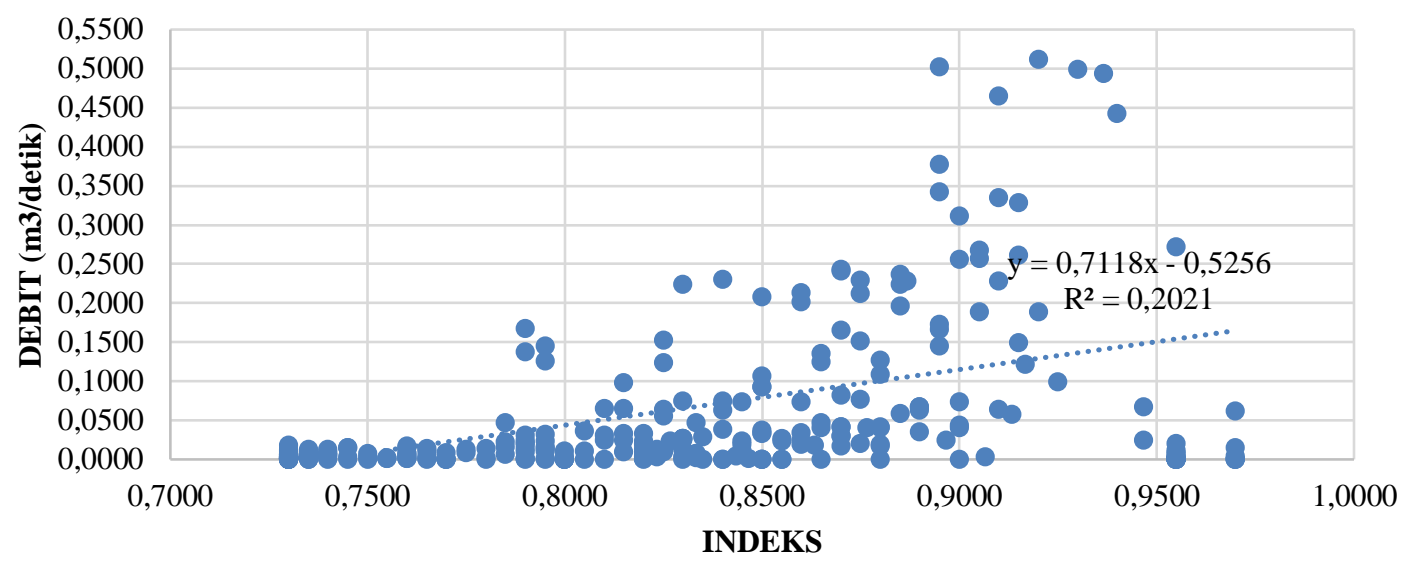

Gambar 1 Grafik Korelasi antara Debit Ketersediaan Air dan Indeks

Dari grafik diatas maka trend bencana kekeringan yang akan datang dapat diperkirakan menggunakan persamaan linier $\mathrm{y}=0,7118 \mathrm{x}-0,5256$ dengan $\mathrm{y}$ debit dan $\mathrm{x}$ adalah indek.

\section{Pemetaan Kekeringan}

Hasil analisa perhitungan indeks kekeringn berdasarkan metode Moisture Adequacy Index selanjutnya diklasifikasikan setelah itu dipetakan menggunakan software ArcGIS. Warna dalam pemetaan kekeringan berubah dari hijau ke merah tua, basah ke kering. Pemetaan kekeringan dapat dilihat pada Gambar 3.

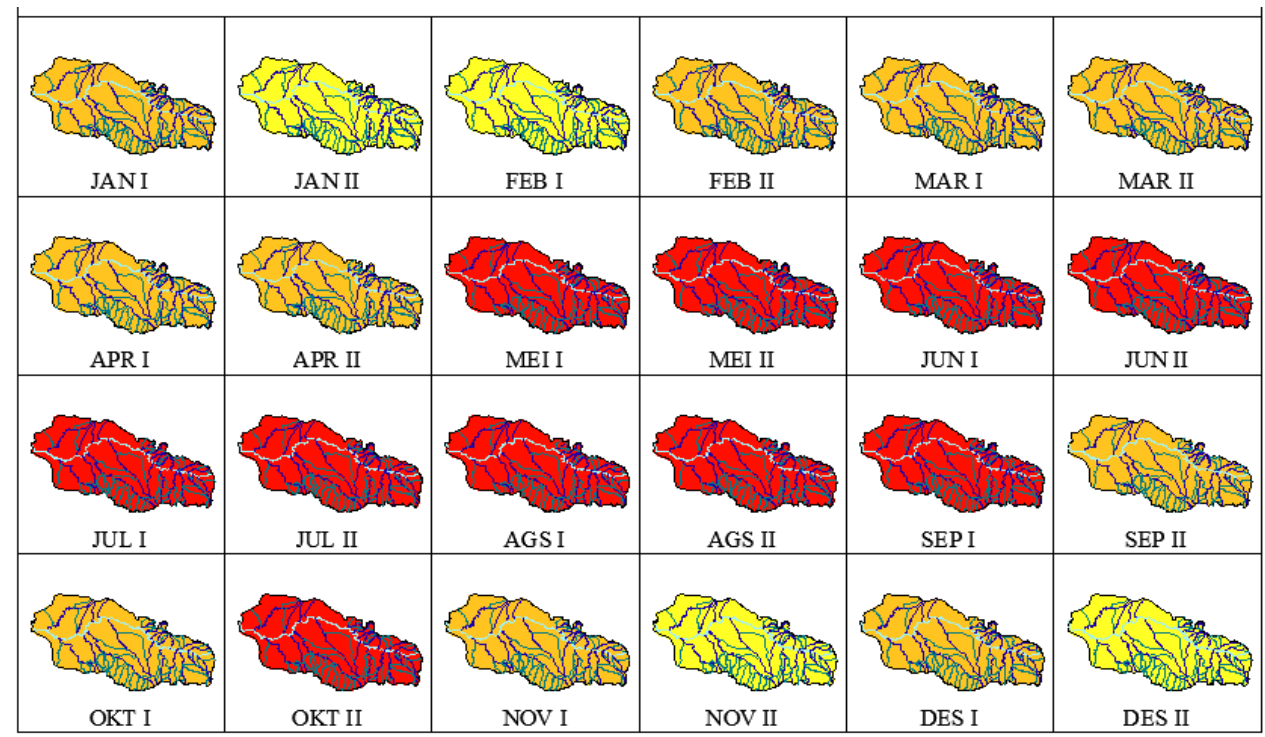

Gambar 17. Pemetaan Tahun 2017

Keterangan : \} \text { Kering Sedang } \ \text { Kering Ringan } \quad \text { Normal } 


\section{KESIMPULAN}

Kesimpulan yang dapat diambil berdsarkan hasil perhitungan yang telah dilakukan untuk analisa kekeringan yaitu :

1 Nilai evapotranspirasi aktual berada pada rentang 15,2046 $\mathrm{mm}$ hingga 230,6536 mm. Sedangkan evapotranspirasi potensial berada pada rentang 19,2463 $\mathrm{mm}$ hingga 297,6175 mm. Faktor yang mempengaruhi besar evapotranspirasi aktual yaitu suhu udara, jumlah hari hujan, dan exposed surface, sedangkan pada evapotranspirasi potensial faktor yang mempengaruhi adalah suhu udara.

2 Klasifikasi kekeringan menggunakan CAZRI Central Arid Zone Research Institute) dan diperoleh bahwa indeks kekeringan yang telah diperoleh berdasarkan metode Moisture Adequacy Index memiliki rentang kriteria kekeringan sedang hingga normal.

3 Grafik hubungan antara debit ketersediaan air dan index dibuat guna mengetahui trend bencana kekeringan berupa besar debit jika diketahui indeks (berdasarkan persamaan) yang terjadi di Daerah Aliran Sungai (DAS) Temon, persamaan yang diperoleh dari grafik scatter plot yaitu y $=0,7118 \mathrm{x}-0,5256$ dengan y debit dan $\mathrm{x}$ adalah indeks.

4 Dari hasil perhitungan indeks kekeringan berdasarkan metode Moisture Adequacy Index, nilai minimum indeks kekeringan selama 15 tahun yaitu 0,73 pada kriteria kekeringan sedang dan nilai maksimum indeks kekeringan yaitu 0,97 pada kriteria normal.

Pemetaan kekeringan dibuat guna mengetahui persebaran kekeringan setiap 15 hari yang nantinya dapat digunakan sebagai mitigasi bencana kekeringan di Daerah Aliran Sungai (DAS) Temon dan sekitarnya pada periode berikutnya. Warna pada pemetaan kekeringan bergradasi kuning ke merah dengan maksud keadaan normal ke kering sedang

\section{DAFTAR PUSTAKA}

Henny Pratiwi Adi. 2011. Kondisi dan Konsep Penanggulanan Bencana Kekeringan di Jawa Tengah. Fakultas Teknik Universitas Islam Sultan Agung, Semarang.

Rintis Hadiani. 2009. Analisis Kekeringan Berdasarkan Data Hidrologi. Disertasi, UNIBRAW. Malang

A. A. L. N Sarma. 1983. Moisture adequacy in relation to forestry and agricultural land use in the Mahanadi River Basin. Department of Meterology and Oceanography. India.

Ika Suryanti, Heny Suharsono, Aris Pramudia. 2008. Analisis Hubungan Antara Sebaran Kekeringan Menggunakan Indeks Palmer dengan Karakteristik Kekeringan. Laporan Tugas Akhir Fakultas Matematika dan Ilmu Pengetahuan Alam Proram Studi Metereologi, Institut Pertanian Bogor.

Puguh Dwi Raharjo. 2010. Teknik Penginderaan Jauh dan Sistem Informasi Geografis untuk Identifikasi Potensi Kekeringan. Makara, Teknologi, Vol.14 No.2, November. Balai Informasi dan Konservasi Kebumian, Karangsembung, Lembaga Ilmu Pengetahuan Indonesia, Kebumen.

Badan Standarisasi Nasional. 2012. SNI 7745 : 2012 Tata Cara Perbitungan Evapotranspirasi Tanaman Acuan dengan Metode Penman - Monteith. Jakarta

Mock, F.J. 1973. Land Capability Appraisal Indonesia. Water Avaibility Appraisal Report Prepared for the Land Capability Appraisal Project. Bogor-Indonesia. 